\title{
PENERAPAN AHP (ANALITYCAL HIERARCHY PROCESS) UNTUK MEMAKSIMALKAN PEMILIHAN VENDOR PELAYANAN TEKNIK DI PT. PLN (PERSERO) AREA BANYUWANGI
}

\author{
Harliwanti Prisilia \\ Jurusan Teknik Industri \\ Universitas 17 Agustus 1945 Banyuwangi \\ Jl.Adi Sucipto No.26 Banyuwangi 68416 \\ harliwantip@yahoo.com
}

\begin{abstract}
Abstrak
Pelaksanaan pekerjaan pelayanan teknik di PLN dibantu oleh vendor atau rekanan terseleksi. Pelelangan pekerjaan pelayanan teknik cenderung dilakukan hanya untuk mendapatkan harga serendah mungkin, yaitu dengan menggunakan banyak vendor dengan perjanjian jangka pendek. Kondisi tersebut menimbulkan dampak tersendiri disisi pelayanan PLN kepada pelanggan.Tujuan dari penelitian ini adalah untuk menerapkan metode AHP guna mendapatkan vendor terbaik sebagai pelaksana pelayanan teknik. Proses pemilihan vendor yang selama ini dilakukan oleh PLN masih mempunyai kelemahan dalam hal kualitas dari pekerjaan vendor pelayanan teknik yang kurang optimal dan professional. PLN sebagai perusahaan yang memiliki wewenang dalam pelaksanaan pelelangan pekerjaan pelayanan teknik, mengalami beberapa kendala diantaranya masih mendapatkan vendor yang tidak sesuai klasifikasi. Metode AHP ini membantu PLN dalam memecahkan persoalan yang kompleks dengan menstruktur suatu hirarki kriteria, pihak yang berkepentingan, hasil dan dengan menarik berbagai pertimbangan guna mengembangkan bobot atau prioritas. Selain itu AHP juga memiliki perhatian khusus tentang penyimpangan dari konsistensi, pengukuran dan ketergantungan di dalam dan di luar kelompok elemen strukturnya. Sehingga PLN memiliki vendor pelayanan teknik yang berkualitas dalam melayani pelanggan.Hasil dari penelitian menunjukkan vendor yang terpilih adalah PT.APP dengan bobot nilai $59 \%$.
\end{abstract}

Kata kunci : Vendor, AHP, bobot nilai.

\section{LATAR BELAKANG}

Vendor adalah lembaga, perorangan atau pihak ketiga yang menyediakan bahan, jasa, produk untuk diolah atau dijual kembali atau dibutuhkan oleh perusahaan untuk meningkatkan kinerja perusahaan. Vendor mempunyai peranan penting dalam proses bisnis PLN (Perusahaan Listrik Negara) dan saat ini manajemen pemilihan vendor menjadi sorotan di PLN karena pemilihan vendor menjadi bagian dari sebuah proses perubahan, Sehingga sangat berpengaruh terhadap kelangsungan pelayanan teknik PLN.

Sebagai perusahaan yang bergerak di bidang pendistribusian atau penjualan energi listrik, PLN harus dapat memberikan produk jasa berkualitas, dengan cara mengadakan lelang pada setiap pekerjaannya. Salah satunya dengan mengadakan lelang pekerjaan pelayanan teknik. Hasil evaluasi lelang pekerjaan pelayanan teknik cenderung dilakukan hanya untuk mendapatkan harga serendah mungkin,hasil kerja kurang memuaskan,waktu pekerjaan lama,kompetensi kurang,peralatan kerja kurang dan kelengkapan dokumen kurang. Seiring dengan berkembangnya PLN, kecenderungan tersebut sekarang berubah dengan memberikan penekanan lebih pada beberapa klasifikasi.

PLN Sebagai pelaksana pelelangan pekerjaan pelayanan teknik, harus melakukan komunikasi, komitmen, visi dengan vendor, Sehingga dapat menekan resiko gagalnya proyek pemilihan vendor, maupun peserta vendor fiktif.

Melihat betapa pentingnya peranan yang dijalankan PLN dalam melayani listrik kepada pelanggan, Maka penulis berusaha membantu menerapkan metode AHP Dalam menentukan vendor pelayanan teknik.

Metode AHP merupakan metode yang tepat dalam memaksimalkan pemilihan vendor pelayanan teknik terbaik, dengan melibatkan sejumlah preferensi dan responden, criteria 
pilihan serta penyediaan satu skala penilaian tertentu, yang disusun dalam suatu kuesioner sehingga hasil dari evaluasi dengan metode AHP ini dapat memberikan hasil optimum kepada perusahaan dalam meneliti vendor yang berkualitas.

\section{A. Perumusan Masalah}

Sesuai dengan latar belakang masalah diatas, maka dapat dirumuskan masalah penelitian sebagai berikut :

a. Faktor apa yang mempengaruhi proses pemilihan vendor?

b. Berapa bobot faktor yang mempengaruhi proses pemilihan vendor?

c. Bagaimana penerapan software expert choice pada metode AHP untuk melaksanakan proses pemilihan vendor yang terbaik?

\section{B. Tujuan dan Manfaat Penelitian}

Tujuan penelitian :

a. Untuk mendapatkan vendor terbaik sebagai pelaksana pelayanan teknik

b. Untuk meningkatkan pelayanan PLN kepada masyarakat

c. Untuk memperbaiki citra PLN di masyarakat

Manfaat penelitian :

a. Sebagai bahan untuk perbandingan teori dan praktek tentang pemilihan vendor pelayanan teknik sehingga dapat menambah wawasan yang sangat penting bagi peneliti di masa yang akan datang.

b. Sebagai bahan pertimbangan bagi perusahaan dalam menentukan langkah-langkah maupun kebijakan, terutama yang berhubungan dengan pemilihan vendor pelayanan teknik sehingga dapat optimal dalam melaksanakan proses bisnis PLN.

\section{METODE PENELITIAN}

Langkah-langkah Penelitian :

1. Melakukan Observasi Awal

2. Melakukan Identifikasi Masalah

3. Menetapkan Tujuan Penelitian

4. Melakukan Studi Literatur

5. Melakukan Pengumpulan Data

\section{METODE PENGUMPULAN DATA}

Metode dalam pengumpulan data yang digunakan penulis dalam penelitian ini adalah sebagai berikut :

1. Observasi

2. Wawancara (interview)

3. Kuisioner

4. Studi literatur

\section{PENGOLAHAN DATA DAN ANALISA HASIL}

\section{A. Pengolahan data manual}

Pengolahan data manual merupakan salah satu cara penyelesaian suatu masalah AHP dengan menggunakan rumusan manual dengan sumber data dari kuisioner. Perhitungan faktor pembobotan hierarki untuk semua kriteria. Hasil analisa preferensi gabungan dari 9 responden menunjuk hasil sebagai berikut: 
Tabel 1. Matriks faktor pembobotan secara total aspek pemilihan vendor

\begin{tabular}{|c|c|c|c|c|c|c|c|c|c|c|c|c|c|c|c|c|c|c|}
\hline Aspek pem-7ihan vendor & & 1 & 2 & 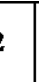 & 3 & 4 & I & 5 & 5 & 6 & 5 & 7 & 7 & 8 & 9 & 9 & Aspek pemilihan vendor & $\begin{array}{c}\text { Nilai } \\
\text { Geomean }\end{array}$ \\
\hline Memiliki ijin usaha & 3 & & 3 & & 5 & 7 & & 3 & & 5 & & & 3 & 3 & 3 & & $\begin{array}{l}\text { Tidak dalam pengawasan } \\
\text { pengadilan }\end{array}$ & 3.69238762 \\
\hline Memiliki ijin usaha & & 9 & 5 & & 7 & 1 & & 3 & & 7 & & 5 & & 9 & & 9 & Memiliki pengalaman & 5.17869747 \\
\hline Memiliki ijin usaha & & 7 & 7 & & 9 & 9 & & 7 & & 3 & & & 7 & 9 & & 7 & $\begin{array}{l}\text { Penyediaan fasilitas dan } \\
\text { peralatan }\end{array}$ & 6.92776616 \\
\hline $\begin{array}{l}\text { Tidak dalam pengawasan } \\
\text { pengadilan }\end{array}$ & & 3 & & 5 & 1 & & 3 & & 5 & 3 & & 5 & & 1 & & 7 & Memiliki pengalaman & 3.06147137 \\
\hline $\begin{array}{l}\text { Tidak dalam pengawasan } \\
\text { pengadilan }\end{array}$ & & 5 & & 3 & 7 & 5 & & & 1 & & 3 & & 3 & 5 & & 3 & $\begin{array}{l}\text { Penyediaan fasilitas dan } \\
\text { peralatan }\end{array}$ & 3.45894515 \\
\hline Memiliki pengalaman & & 3 & 1 & & 3 & 3 & & 3 & & 5 & & 3 & & 1 & 5 & & $\begin{array}{l}\text { Penyediaan fasilitas dan } \\
\text { peralatan }\end{array}$ & 2.63265549 \\
\hline
\end{tabular}

Tabel 2. Matriks pair wise untuk semua kriteria

\begin{tabular}{|l|c|c|c|c|}
\hline \multicolumn{1}{|c|}{ Aspek pemilihan vendor } & Memiliki ijin usaha & $\begin{array}{c}\text { Tidak dalam pengawasan } \\
\text { pengadilan }\end{array}$ & Memiliki pengalaman & $\begin{array}{c}\text { Penyediaan fasilitas dan } \\
\text { peralatan }\end{array}$ \\
\hline Memiliki ijin usaha & 1 & 3.6923876 & 5.1786975 & 6.9277662 \\
\hline $\begin{array}{l}\text { Tidak dalam pengawasan } \\
\text { pengadilan }\end{array}$ & 0.2708275 & 1 & 3.0614714 & 3.4589451 \\
\hline Memiliki pengalaman & 0.1930987 & 0.3266403 & 1 & 2.6326555 \\
\hline $\begin{array}{l}\text { Penyediaan fasilitas dan } \\
\text { peralatan }\end{array}$ & 0.1443467 & 0.2891055 & & 1 \\
\hline Jumlah & 1.6082729 & 5.3081334 & & 1 \\
\hline
\end{tabular}

Dengan unsur-unsur pada tiap kolom dibagi dengan jumlah kolom yang bersangkutan, akan diperoleh bobot relative yang dinormalkan. Nilai vector eigen dihasilkan dari rata-rata bobot relative untuk setiap barisnya. Hasilnya dapat pada table berikut ini :

Tabel 3. Matriks priority untuk semua kriteria

\begin{tabular}{|l|c|c|c|c|c|}
\hline \multicolumn{1}{|c|}{ Aspek penilhan vendor } & Memiliki ijin usaha & $\begin{array}{c}\text { Tidak dalam pengawasan } \\
\text { pengadilan }\end{array}$ & Memilikipengalaman & $\begin{array}{c}\text { Penjediaan fasilitas dan } \\
\text { peralatan }\end{array}$ & $\begin{array}{c}\text { Veetor eigen yang } \\
\text { dinormalkan }\end{array}$ \\
\hline Memiliki ijin usaha & 0.6217850 & 0.6956094 & 0.5383254 & 0.4941569 & 0.5874692 \\
\hline $\begin{array}{l}\text { Tidak dalam pengawasan } \\
\text { pengadilan }\end{array}$ & 0.1683965 & 0.1883901 & 0.3182398 & 0.2467262 & 0.2304382 \\
\hline Memilikipengalaman & 0.1200659 & 0.0615358 & 0.1039500 & 0.1877870 & 0.1183347 \\
\hline $\begin{array}{l}\text { Penyediaan fasilitas dan } \\
\text { peralatan }\end{array}$ & 0.0897526 & 0.0544646 & 0.0394848 & 0.0713299 & 0.0637580 \\
\hline Jumlah & 0.5874692 & 0.2304382 & 0.1183347 & 0.0637580 & 1.000 \\
\hline
\end{tabular}

Kemudian pada setiap kolom matriks pair wise dikalikan dengan vector eigen supaya dihasilkan penjumlahan entri pada setiap kolom. 
Tabel 4. Penjumlahan entri

\begin{tabular}{|c|c|c|c|c|c|}
\hline Aspek peniliban vendar & Memilkiki jijn ussha & $\begin{array}{c}\text { Tidak dalam pengawasan } \\
\text { pengadilan }\end{array}$ & Memiliki pengalaman & $\begin{array}{c}\text { Penyediaan fasilitas dan } \\
\text { peralatam }\end{array}$ & Jumlah \\
\hline Memiliki ijin usaha & 0.5874692 & 0.8508670 & 0.6128195 & 0.4417004 & 2.4928561 \\
\hline $\begin{array}{l}\text { Tidak dalam pengawasan } \\
\text { pengadilian }\end{array}$ & 0.1591028 & 0.2304382 & 0.3627782 & 0.2205354 & 0.9723546 \\
\hline Memiliki pengalaman & 0.1134396 & 0.0752704 & 0.1183347 & 0.1778528 & 0.4748975 \\
\hline $\begin{array}{l}\text { Penyediaan fasilitas dan } \\
\text { peralatan }\end{array}$ & 0.0847992 & 0.0666209 & 0.0449488 & 0.0637580 & 0.2601269 \\
\hline \multicolumn{5}{|c|}{ Jumlah } & 4.2002351 \\
\hline
\end{tabular}

Selanjutnya nilai eigen maksimum ( $\lambda$ maksimum) didapat dengan membagi antara penjumlahan pada kolom entri di bagi dengan vector eigen. Nilai eigen maksimum yang diperoleh adalah :

Tabel 5. Nilai eigen maksimum

\begin{tabular}{|l|c|c|c|}
\hline Aspek pemilihan vendor & Penjumlahan entri & Matriks Priority & $\lambda$ Maks (A/B) \\
\hline Memiliki ijin usaha & 2.4928561 & 0.5874692 & 4.2433820 \\
\hline $\begin{array}{l}\text { Tidak dalam pengawasan } \\
\text { pengadilan }\end{array}$ & 0.9723546 & 0.2304382 & 4.2195901 \\
\hline Memiliki pengalaman & 0.4748975 & 0.1183347 & 4.0131722 \\
\hline $\begin{array}{l}\text { Penyediaan fasilitas dan } \\
\text { peralatan }\end{array}$ & 0.2601269 & 0.0637580 & 4.0799113 \\
\hline Jumlah & & & 16.5560556 \\
\hline$\lambda$ maksimum & & & 4.1390139 \\
\hline
\end{tabular}

Karena matriks berordo 4 (terdiri dari 4 kriteria), Nilai indeks konsistensi yang diperoleh adalah :

Untuk $n=4, \mathrm{RI}=0.900$ (table saaty), Maka :

$$
\begin{aligned}
& \mathrm{CI}=\frac{\left(\lambda_{\max }-\mathrm{n}\right)}{(\mathrm{n}-1)}=\frac{4.139-4}{4-1}=0.046 \\
& \mathrm{CR}=\frac{\mathrm{CI}}{\mathrm{RI}}=\frac{0.046}{0.900}=0.051
\end{aligned}
$$

Karena $C R<0.100$, Berarti responden adalah konsisten.

Dari hasil perhitungan pada table diatas menunjukkan bahwa klasifikasi memiliki ijin usaha paling penting dengan bobot $58.74 \%$, Berikutnya adalah klasifikasi tidak dalam pengawasan dengan nilai bobot $23.04 \%$, Kemudian klasifikasi memiliki pengalaman dengan nilai $11.83 \%$ dan klasifikasi penyediaan fasilitas dan peralatan dengan nilai bobot $6.3 \%$. 


\section{B. Analisa hasil}

Dari hasil perhitungan manual dan menggunakan expert choice, dapat disimpulkan pada table berikut :

Tabel 6. perbandingan hitungan manual dengan expert choice

\begin{tabular}{|c|c|c|c|c|c|c|c|c|c|c|}
\hline \multirow{2}{*}{ Kriteria } & \multirow{2}{*}{$\begin{array}{l}\text { Hitung } \\
\text { manual }\end{array}$} & \multirow{2}{*}{$\begin{array}{l}\text { Expert } \\
\text { Choice }\end{array}$} & \multirow{2}{*}{ Altematif } & \multirow{2}{*}{ Hitung manual } & \multirow{2}{*}{$\begin{array}{l}\text { Expert } \\
\text { Choice }\end{array}$} & \multirow{2}{*}{ Peserta } & \multirow{2}{*}{$\begin{array}{l}\text { Hitung } \\
\text { manual }\end{array}$} & \multirow{2}{*}{$\begin{array}{l}\text { Expert } \\
\text { Choice }\end{array}$} & \multicolumn{2}{|c|}{ TOTAL } \\
\hline & & & & & & & & & fitungmanud & Expert Choice \\
\hline \multirow{8}{*}{$\begin{array}{l}\text { Menillijijin } \\
\text { usaha }\end{array}$} & \multirow{8}{*}{0.587} & \multirow{8}{*}{0.592} & \multirow{4}{*}{ Bukti ïjin usaha } & \multirow{4}{*}{0.755} & \multirow{4}{*}{0.750} & PT.APP & 0.592 & 0.595 & 0.263 & 0.264 \\
\hline & & & & & & PT. Dewi Riski & 0.225 & 0.226 & 0.100 & 0.100 \\
\hline & & & & & & PTAlwijaya & 0.112 & 0.11 & 0.050 & 0.049 \\
\hline & & & & & & CV. Duta Surya & 0.068 & 0.068 & 0.030 & 0.030 \\
\hline & & & \multirow{4}{*}{ Sertifikatkdas usaha } & \multirow{4}{*}{0.247} & \multirow{4}{*}{0.25} & PT.APP & 0.59 & 0.594 & 0.085 & 0.088 \\
\hline & & & & & & PT. Dewi Riski & 0.225 & 0.226 & 0.033 & 0.033 \\
\hline & & & & & & PTAlwijaya & 0.117 & 0.113 & 0.017 & 0.017 \\
\hline & & & & & & CV. Duta Surya & 0.066 & 0.067 & 0.011 & 0.010 \\
\hline \multirow{8}{*}{$\begin{array}{l}\text { Tidak dalam } \\
\text { pengarasan } \\
\text { pergadtan }\end{array}$} & \multirow{8}{*}{0.230} & \multirow{8}{*}{0.231} & \multirow{4}{*}{$\begin{array}{l}\text { Surnatketerangan } \\
\text { pengendilan }\end{array}$} & \multirow{4}{*}{0.785} & \multirow{4}{*}{0.783} & PI.APP & 0.586 & 0.59 & 0.106 & 0.107 \\
\hline & & & & & & PT. Dewi Riski & 0.233 & 0.235 & 0.042 & 0.043 \\
\hline & & & & & & PTAlwijaya & 0.114 & 0.109 & 0.021 & 0.000 \\
\hline & & & & & & CV. Duta Surya & 0.065 & 0.066 & 0.012 & 0.012 \\
\hline & & & \multirow{4}{*}{$\begin{array}{l}\text { Suratketerangan } \\
\text { kepolisian }\end{array}$} & & & PT.APP & 0.587 & 0.59 & 0.028 & 0.030 \\
\hline & & & & 0215 & 0317 & PT. Dewi Riski & 0.231 & 0.235 & 0.011 & 0.012 \\
\hline & & & & 0.216 & 021 & PTAlwijaya & 0.115 & 0.109 & 0.006 & 0.005 \\
\hline & & & & & & CV. Duta Surya & 0.065 & 0.066 & 0.008 & 0.003 \\
\hline & & & & & & PI.APP & 0.589 & 0.585 & 0.056 & 0.053 \\
\hline & & & Jeris pekerjaan yang & 0708 & 0706 & PT. Dewi Riski & 0.232 & 0.241 & 0.02 & 0.02 \\
\hline & & & pernahditangani & 0.150 & Q.rs & PTAlwijaya & 0.115 & 0.107 & 0.011 & 0.010 \\
\hline Menililij & 0118 & 0114 & & & & CV. Duta Surya & 0.067 & 0.067 & 0.006 & 0.006 \\
\hline pengalaman & 0.110 & 0.114 & & & & PI.APP & 0.594 & 0.618 & 0.014 & 0.014 \\
\hline & & & & 09 & $03 M$ & PT. Dewi Riski & 0.220 & 0.216 & 0.006 & 0.005 \\
\hline & & & Unityang permano rangent & 0.201 & 0204 & PTAlwijaya & 0.113 & 0.105 & 0.008 & 0.002 \\
\hline & & & & & & CV. Duta Surya & 0.063 & 0.061 & 0.001 & 0.001 \\
\hline & & & & & & PI.APP & 0.586 & 0.596 & 0.030 & 0.031 \\
\hline & & & Infter foilitac & 0819 & 0818 & PT. Dewi Riski & 0.233 & 0.231 & 0.012 & 0.012 \\
\hline & & & Dantrar raslinas & 0.819 & 0.818 & PTAlwijaya & 0.117 & 0.111 & 0.006 & 0.006 \\
\hline fengeulad & חก⿻? & 0063 & & & & CV. Duta Surya & 0.062 & 0.062 & 0.008 & 0.003 \\
\hline lasslitas can & 0.063 & Lulos & & & & PT.APP & 0.598 & 0.608 & 0.000 & 0.007 \\
\hline & & & Ingttre repto & 0190 & 0187 & PT. Dewi Riski & 0.219 & 0.23 & 0.00 & 0.003 \\
\hline & & & 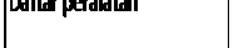 & 0.100 & 0.162 & PT Alwijaya & 0.13 & 0.114 & 0.001 & 0.001 \\
\hline & & & & & & CV. Duta Surya & 0.057 & 0.056 & 0.001 & 0.001 \\
\hline & & & & Iotal & & & & & 1000 & 1.000 \\
\hline
\end{tabular}

\section{KESIMPULAN DAN SARAN}

A. Kesimpulan

Dari hasil penelitian dengan menggunakan perhitungan manual AHP serta expert choice dapat diketahui bahwa nilai akhir (urutan rangking) dari masing-masing klasifikasi pemilihan vendor pelayanan teknik sebagai berikut:

Faktor yang mempengaruhi kriteria pemilihan vendor pelayanan teknik adalah :

1. Memiliki ijin usaha dengan bobot nilai $58.7 \%$

2. Tidak dalam pengawasan pengadilan dengan bobot nilai $23 \%$

3. Memiliki pengalaman dengan bobot nilai $11.8 \%$

4. Penyediaan fasilitas dan peralatan dengan bobot nilai $6.3 \%$ 
Sedangkan bobot faktor yang mempengaruhi proses pemilihan vendor pelayanan teknik sebagai berikut :

1. Alternatif Memiliki ijin usaha :

a. Bukti ijin usaha dengan bobot nilai $75.5 \%$

b. Sertifikat kelas usaha dengan bobot nilai $24.7 \%$

2. Alternatif tidak dalam pengawasan pengadilan :

a. Surat keterangan pengadilan dengan bobot nilai $78.5 \%$

b. Surat keterangan kepolisian dengan bobot nilai $21.5 \%$

3. Alternatif memiliki pengalaman :

a. Jenis pekerjaan yang pernah ditangani dengan bobot nilai $79.8 \%$

b. Unit yang pernah ditangani dengan bobot nilai $20.1 \%$

4. Alternatif penyediaan fasilitas dan peralatan :

a. Daftar fasilitas dengan bobot nilai $81.9 \%$

b. Daftar peralatan dengan bobot nilai $18 \%$

Sedangkan urutan prioritas vendor pelayanan teknik dengan mempertimbangkan seluruh kriteria sebagai berikut :

1. PT. APP dengan bobot nilai $59 \%$

2. PT. Dewi Riski dengan bobot nilai $23 \%$

3. PT. Alwijaya dengan bobot nilai $12 \%$

4. CV. Duta Surya dengan bobot nilai $6 \%$

Dari hasil urutan prioritas diatas dapat diketahui bahwa vendor yang terpilih adalah PT. APP karena PT. APP merupakan perusahaan yang memiliki kelengkapan administrasi, Tidak pernah bermasalah dalam menangani jasa pemborongan pelayanan teknik serta memiliki kelengkapan fasilitas, Peralatan, Personil yang handal serta sudah terpercaya menangani jasa pemborongan pelayanan teknik di PLN wilayah sejawa timur. Sehingga para responden cenderung memilih PT. APP untuk mengani jasa pelayanan teknik di PLN banyuwangi.

\section{B. Saran}

Dari hasil analisa yang telah dilakukan, penulis dapat memberikan beberapa saran diantaranya :

1. Dengan adanya metode expert choise ini diharapkan tidak ada lagi permasalahan pada saat pelaksanaan pemilihan vendor pelayanan teknik.

2. Metode expert choise ini mungkin dapat diterapkan bukan hanya untuk pemilihan vendor pelayanan teknik, Akan tetapi pada saat pemilihan vendor untuk pekerjaan pemeliharaan dan pembangunan jaringan. 


\section{DAFTAR PUSTAKA}

[1] Keputusan direksi PT. PLN (Persero) Nomor : 080.K/DIR/2008.

[2] Saaty, T.L. 1993. Pengambilan Keputusan Bagi Para Pemimpin, Proses Hirarki Analitik untuk Pengambilan Keputusan dalam Situasi yang Kompleks. Jakarta: PT. Pustaka Binaman Pressindo.

[3] Marimin, (2004). Teknik dan Aplikasi Pengambilan Keputusan Kriteria Mejemuk. Jakarta: PT.Grasindo.

[4] Team Fakultas Teknik, 2013. Panduan Kerja Praktek dan Tugas Akhir. Banyuwangi, Universitas 17 Agustus 1945 Banyuwangi.

[5] Keputusan Menteri Tenaga Kerja dan Transmigrasi Republik Indonesia Nomor: KEP.101/MEN/VI/2004

[6] Undang-Undang No.13 Tahun 2003 Tentang Ketenagakerjaan

[7] Usmara. (2003). Handbook of Organizations : Kajian dan Teori Organisasi. Yogyakarta : Amara Books.

[8] Ariesanti, Yusia (2008), Implementasi Pendekatan Metode MCDM - ELECTRE III dan Fuzzy PERT dalam Perangkingan dan Penjadwalan Proyek, Surabaya, Tugas Akhir Jurusan Teknik Industri ITS. 